\title{
HtpG, the Porphyromonas gingivalis HSP-90 homologue, induces the chemokine CXCL8 in human monocytic and microvascular vein endothelial cells
}

Charles E. Shelburne, ${ }^{1 *}$ Malini D. Coopamah, ${ }^{1}$ Domenica G. Sweier, ${ }^{2}$ Florence Y.-P. $\mathrm{An}^{1}$ and Dennis E. Lopatin ${ }^{1}$

Departments of ${ }^{1}$ Biologic and Materials Sciences and ${ }^{2}$ Cariology, Restorative Sciences and Endodontics, School of Dentistry, The University of Michigan, Ann Arbor, MI 48108, USA.

\section{Summary}

CXCL8 (interlukin 8, IL-8) has a diverse spectrum of biological activities including $T$ cell, neutrophil and basophil chemotactic properties. It is produced by a wide variety of cell types and plays a significant role in the initiation of the acute inflammatory response. During inflammation, CXCL8 attracts and activates leukocytes at the site of infection leading to leukocyte infiltration, which can lead to tissue damage. Porphyromonas gingivalis, an aetiological agent of periodontitis, induces production of CXCL8 from several types of cells via its LPS and outer membrane proteins. Bacterial chaperones elicit a strong pro-inflammatory response in cells of the innate immune system. In $P$. gingivalis the htpG gene codes for the homologue of human Hsp90, a chaperone that associates with transcription factors, hormone receptors and protein kinases, affecting signal transduction pathways. CXCL8 mRNA and CXCL8 protein production was induced in monocytic/human microvascular vein endothelial cells treated with $\boldsymbol{P}$. gingivalis cells or rHtpG protein. Blocking of receptors CD91 and TLR4 reduced the production of CXCL8 by rHtpG either using receptor-specific antibody or by siRNA silencing. Pre-incubation of $P$. gingivalis rHtpG preparations with human anti-HtpG significantly inhibited CXCL8 production. A P. gingivalis HtpG disruption mutant also induced less CXCL8 mRNA and protein. These results suggest that $P$. gingivalis HtpG might be involved in CXCL8-mediated immunopathogenesis.

Received 3 August, 2006; revised 18 December, 2006; accepted 30 December, 2006. *For correspondence. E-mail ceshelbu@ umich.edu; Tel. (+1) 734975 0946; Fax (+39) 7349759329.

\author{
Introduction
}

Chronic infection with Porphyromonas gingivalis is strongly correlated to periodontitis and is an important risk factor for the maintenance and progression of the disease (Socransky and Haffajee, 1992; 1997). It is also frequently found in atherosclerotic plaques, presumably via minor bacteremias associated with personal or professional oral hygiene (Coulter et al., 1990; McLaughlin et al., 1996; Kozarov et al., 2006). This chronic infection associates adaptive lymphocyte immunity with innate immunity to produce local infiltration of neutrophils, macrophages and $\mathrm{T}$ and $\mathrm{B}$ cells specific for a plethora of $P$. gingivalis antigens (Cutler et al., 1991; 1999). Chronic inflammation is initiated and maintained by chemokines and cytokines that are secreted by gingival epithelial cells and macrophages. CXCL8 is one of the principal mediators of this inflammatory response.

CXCL8 is a member of the C-X-C family of chemokines that has a diverse spectrum of biological activities including $T$ cell, neutrophil and basophil chemotactic properties (Gangur et al., 2002; Robertson, 2002; Gear and Camerini, 2003). It can be produced by a wide variety of cell types and is believed to play a significant role in the initiation of the acute inflammatory response (Balasubramanian et al., 2005; Barker et al., 2005; Lin et al., 2005; Skjolaas et al., 2006). In the course of inflammation, CXCL8 attracts leukocytes to the site of infection leading to neutrophil infiltration, which may subsequently culminate in epithelial cell damage (Baggiolini, 1998). Therefore, its downregulation is vital in the prevention of chronic inflammation. A number of bacterial surface molecules such as LPS and heat-shock proteins (Hsps) are closely associated with inflammation. LPS-induced production of inflammatory molecules via toll-like receptors (TLR) on a number of host epithelial cells (Bainbridge et al., 2002; Darveau et al., 2002) has been reported, including human microvascular vein endothelial cells (HMVEC) which may suggest a role for $P$. gingivalis in the initiation of cardiovascular plaque (Coats et al., 2003).

Heat-shock proteins are a group of evolutionary conserved proteins ranging in size from $8 \mathrm{kDa}$ to $150 \mathrm{kDa}$ that are synthesized rapidly by most cells responding to stress-related events (Kaufmann, 1990). They act as 
Table 1. Selected increase in cytokine mRNA in THP-1 cells treated with rHtpG.

\begin{tabular}{lcccr}
\hline & \multicolumn{3}{c}{$\begin{array}{c}\text { Fold increase in mRNA by THP-1 cells after } \\
\text { treatment with rHTPG }\left(\mu \mathrm{ml}^{-1}\right) \text { for } 30 \mathrm{~min}\end{array}$} \\
\cline { 2 - 5 } Cytokine & 0 & 1 & 10 & 50 \\
\hline IL-1 $\alpha$ & 1.0 & 0.7 & 0.7 & 1.2 \\
IL-1 & 1.0 & 0.7 & 1.1 & 4.9 \\
CXCL8 & 1.0 & 0.9 & 2.5 & 14.9 \\
TNF $\alpha$ & 1.0 & 0.9 & 1.0 & 4.3 \\
\hline
\end{tabular}

chaperones through protein-protein interaction to protect proteins from denaturation during synthesis or during noxious processes including heat stress, infection and inflammation. The chaperones of several bacteria including Campylobacter rectus (Hinode et al., 1998), Heliobacter pylori (Lin et al., 2005) and Chlamydia pneumoniae (Da Costa et al., 2004) have been reported to induce the production of CXCL8 in a number of cells including human gingival fibroblasts, endothelial cells and monocytic cells (Bulut et al., 2002). Therefore, we speculated that $P$. gingivalis $\mathrm{HtpG}$ might also be involved in the modulation of CXCL8 in monocytic or HMVEC cells.

To investigate the mechanisms of monocyte and HMVEC activation associated with HtpG, we cloned whole $\mathrm{HtpG}$ and produced a disruption mutant of the gene (Sweier et al., 2003). We report here that CXCL8 was secreted from monocytic cells (THP-1) and HMVEC following treatment with $\mathrm{rHtpG}$ and that CXCL8 induction was inhibited by pre-treatment of the protein with human antibody to rHtpG. We also describe reduced CXCL8 mRNA and CXCL8 protein production in monocytic cells treated with the htpG disruption mutant compared with those treated with the parent strain. Finally, we show that rHtpG induces CXCL8 by interaction with at least two types of surface molecules, TLR and scavenger receptors.

\section{Results}

Porphyromonas gingivalis HtpG induces CXCL8 mRNA and protein in human monocytic cells

We examined the CXCL8-specific mRNA and protein response to treatment with $\mathrm{rHtpG}$ by culturing the cells with dilutions of rHtpG. Determination of a proinflammatory cytokine, TNF $\alpha$, was included in some experiments for comparison.

Fold increases up to 14 for CXCL8 and TNF $\alpha$ mRNA were observed by reverse transcription polymerase chain reaction (RT-PCR) of THP-1 cells treated with 1, 10 and $50 \mu \mathrm{g} \mathrm{ml}^{-1}$ concentrations of $\mathrm{rHtpG}$ as measured by the RT-PCR array (Table 1). Similar results were observed using Affymetrix microarray Hu133a and single-tube RT-PCR assays using different primers for the same cytokines (data not shown). When we measured CXCL8 and TNF $\alpha$ protein production in the THP-1 cells there was also dose-response to $\mathrm{rHtpG}$ (Fig. 1). As expected, we also found a dose-response production of CXCL8 and TNF $\alpha$ when THP-1 cells were treated with $P$. gingivalis LPS.

Porphyromonas gingivalis htpG disruption mutant induces less CXCL8 protein than the parent strain

We examined production of CXCL8 protein in THP-1 cells treated with $P$. gingivalis W83 or the disruption mutant W83 4 tpG (Sweier et al., 2003) using a protein microarray (Table 2 ). We were able to detect increases in the production of IL- $1 \alpha, \mathrm{IL}-1 \beta, \mathrm{CXCL} 8$ and TNF $\alpha$ when the W83 parent or mutant were combined with THP-1 cells at a ratio of 100:1 as compared with untreated THP-1 cells. There was no change in the production of INF $\gamma$ or GMSF in the treated cells compared with the untreated cells. However, there was a significant $(P=0.01)$ reduction in the levels of IL- $1 \alpha, \mathrm{IL}-1 \beta, \mathrm{CXCL} 8$ and TNF $\alpha$ when the W83 $\Delta$ tp G cells were compared with the parent strain.

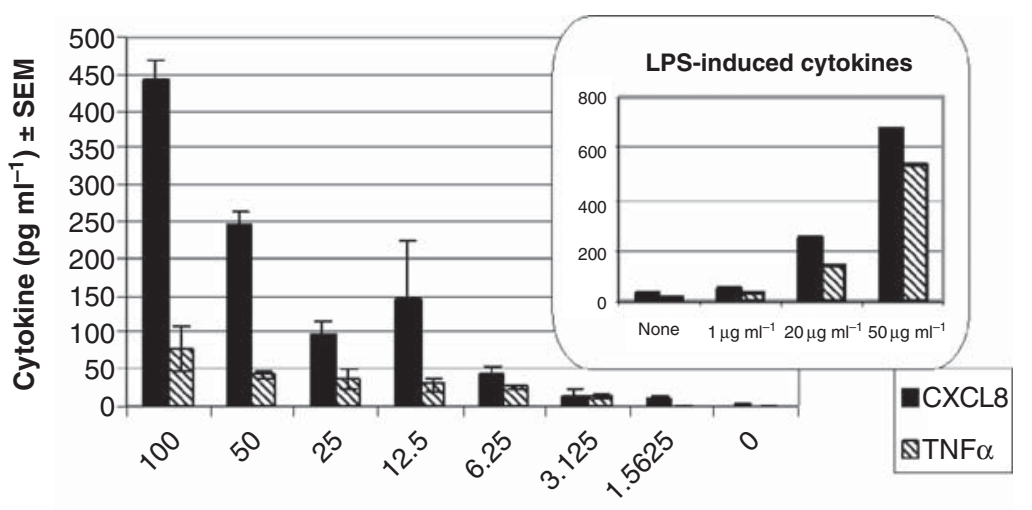

Fig. 1. Cytokine production in THP-1 cells treated with rHtpG. Cells were combined with $\mathrm{rHtpG}$ at the indicated concentration for $8 \mathrm{~h}$. CXCL8 production was determined by ELSIA and is expressed as mean \pm SEM. Inset: CXCL8 production in cells treated with $P$. gingivalis LPS at indicated concentrations.

$\mathrm{HtpG}\left(\mu \mathrm{g} \mathrm{ml}^{-1}\right)$ 


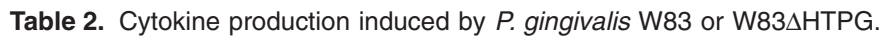

\begin{tabular}{|c|c|c|c|}
\hline \multirow[b]{2}{*}{ Cytokine } & \multicolumn{3}{|c|}{ Cytokine concentration $\left(\mathrm{pg} \mathrm{ml}^{-1}\right)$ after treatment of THP-1 cells with } \\
\hline & No treatment & W83 (moi 100) & W83- $\Delta$ HTPG (moi 100) \\
\hline $\mathrm{IL}-1 \alpha$ & 6.2 & 144.6 & $72.5^{\star}$ \\
\hline IL-1 $\beta$ & 2.6 & 609.7 & $149.6^{*}$ \\
\hline CXCL8 & 292.5 & 2019.1 & $1169.4^{*}$ \\
\hline GMCSF & 38.2 & 33.4 & 29.5 \\
\hline IFN $\gamma$ & 248.5 & 218.1 & 225.5 \\
\hline TNF $\alpha$ & 17.5 & 240.9 & $67.7^{*}$ \\
\hline
\end{tabular}

${ }^{*} P=0.01$ compared with W83 (t-test).

Porphyromonas gingivalis $\mathrm{rHtpG}$ induces CXCL8 in endothelial cells but $\mathrm{P}$. gingivalis $L P S$ does not

In HMVEC cells we detected CXCL8 production in response to $\mathrm{rHtpG}$, but not in response to LPS (Fig. 2). There was also very little or no production of TNF $\alpha$ in HMVEC treated with rHtpG (Fig. 3).

\section{Antibodies to cell surface receptors block production of CXCL8 by rHtpG}

It has been suggested that chaperones interact with cell surface receptors to induce signalling pathways, so we examined the effect of blocking two such cell surface receptors, TLR4 and CD91. We found that in HUVEC blocking of CD91 reduced CXCL8 production by $33 \%$; blocking of TLR4 reduced CXCL8 production by $60 \%$. When we simultaneously blocked both receptors the reduction was $96 \%$ (Fig. 4).

siRNA silencing of THP-1 receptor genes reduces induction of CXCL8 by P. gingivalis HtpG

In order to further support our notion that HtpG induced CXCL8 production by binding to CD91 and TLR4 recep-

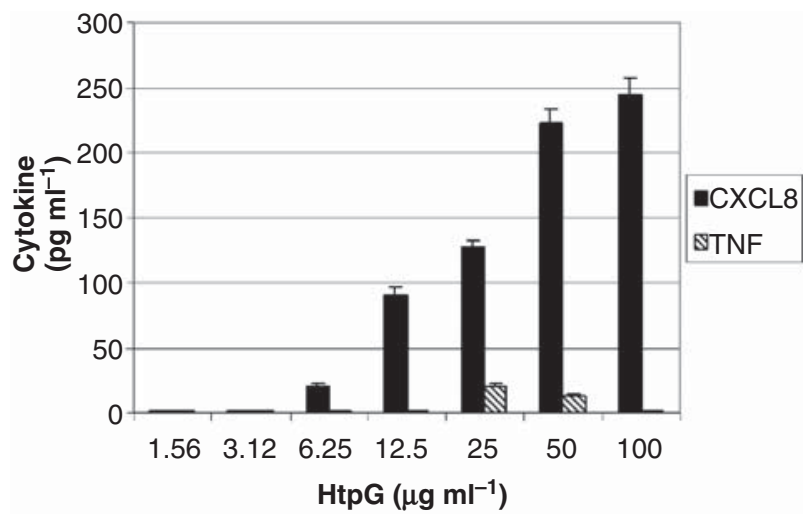

Fig. 2. CXCL8 and TNF production in HMVEC by rHtpG. Cells were combined with rHtpG or $P$. gingivalis LPS at the indicated concentration for $8 \mathrm{~h}$. CXCL8 and TNF $\alpha$ production was determined by ELISA and is expressed as mean \pm SEM. tors, we investigated the chemokine production by THP-1 cells in which the receptors had been substantially eliminated by siRNA gene silencing. The production of CXCL8 protein and mRNA were compared in cells electroporated with siRNA and subsequently either treated with $50 \mu \mathrm{g} \mathrm{ml}^{-1} \mathrm{HtpG}$ or left untreated. siRNA treatment of THP-1 cells reduced CXCL8 production by $80 \%$ when

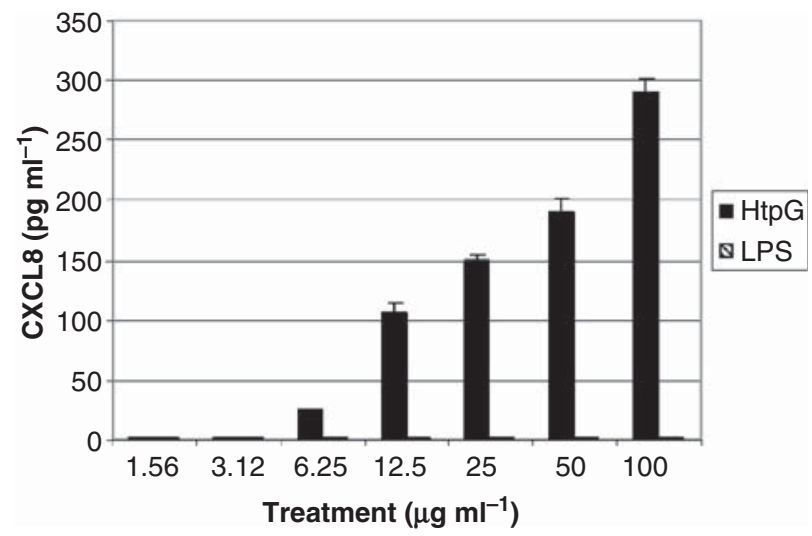

Fig. 3. CXCL8 production in HMVEC cells induced by HtpG or LPS. Cells were combined with rHtpG or $P$. gingivalis LPS at the indicated concentration for $8 \mathrm{~h}$. CXCL8 production was determined by ELISA and is expressed as mean \pm SEM.

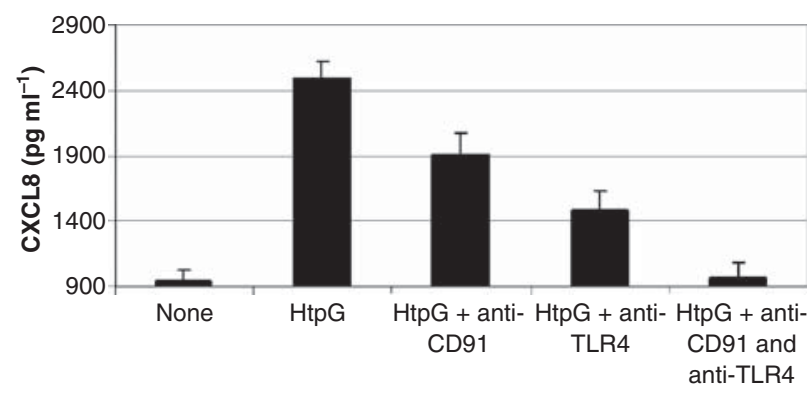

Fig. 4. Effect of anti-CD91 and anti-TLR4 on HtpG induction of CXCL8 in HUVEC. Cells were untreated (None); treated with $50 \mu \mathrm{g} \mathrm{ml}^{-1}$ rHTPG (HtpG); treated with $50 \mu \mathrm{g} \mathrm{ml}^{-1}$ rHTPG after pre-treatment with $1 \mu \mathrm{g} \mathrm{ml}^{-1}$ anti-CD91 (HtpG + anti-CD91) or $1 \mu \mathrm{g} \mathrm{ml}^{-1}$ anti-TLR4 (HtpG + anti-TLR4) or $1 \mu \mathrm{g} \mathrm{ml}^{-1}$ of both anti-CD91 and anti-TLR4 (HtpG + anti-CD91 and anti-TLR4). Results are mean CXCL8 production $\left(\mathrm{pg} \mathrm{ml}^{-1}\right) \pm \mathrm{SEM}$. 


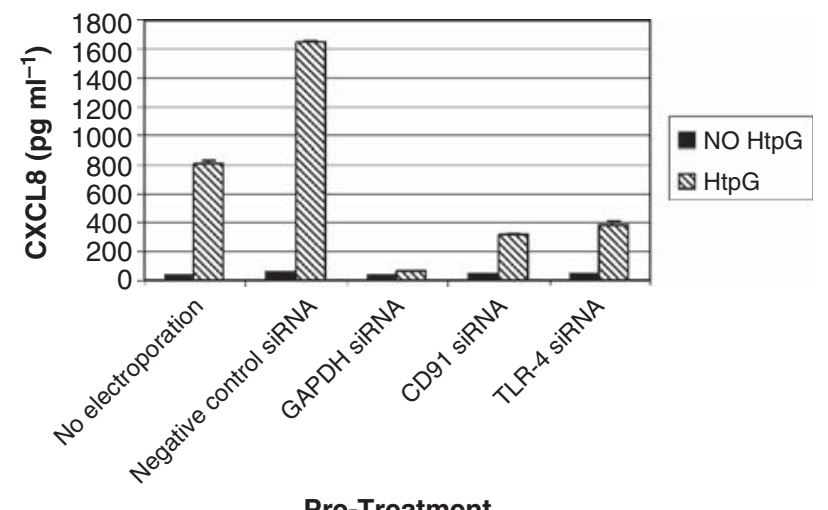

Pre-Treatment

Fig. 5. Effect of siRNA silencing on rHTPG induction of CXCL8 in THP-1 cells. Cells were electroporated with siRNA for either CD91 or TLR4, allowed to recover for $48 \mathrm{~h}$ and then incubated for $8 \mathrm{~h}$ with $50 \mu \mathrm{g} \mathrm{ml}^{-1} \mathrm{rHTPG}$. CXCL8 production was determined by ELISA and is expressed as mean \pm SEM.

CD91 was silenced and $77 \%$ when TLR4 was silenced (Fig. 5). Quantitative RT-PCR confirmed that mRNA for both receptors was reduced simultaneously (data not shown).

\section{Serum antibody to HtpG reduces CXCL8 production in vitro}

We measured the antibody levels to $\mathrm{rHtpG}$ in total IgG purified from 10 subjects participating in a geriatric oral science programme at the University of Michigan (Loesche et al., 1995) and found that eight of the 10 selected serum samples had measurable titres of IgG antibody to $\mathrm{rHtpG}$ (Table 3). When we treated the THP-1 cells with a mixture of $\mathrm{rHtpG}$ and IgG there was a reduction in the production of CXCL8. IgG from serum samples without HtpG antibody did not reduce the production of CXCL8 by the target cells. We made dilutions of IgG from one serum sample and found that there was a doseresponse between the $\operatorname{lgG}$ and reduction of CXCL8 production. There was also a trend for IgG from serum samples with higher titres of anti-HtpG to demonstrate greater reductions in CXCL8 production.

\section{Discussion}

CXCL8 is released from cells following stimulation with LPS of $P$. gingivalis and other bacteria and its effects include neutrophil and T-lymphocyte chemotaxis, neutrophil activation and enhanced expression of neutrophil adhesion molecules. CXCL8 was induced following both stimulation by $P$.gingivalis cells and highly purified $P$. gingivalis $\mathrm{rHtpG}$, similar to reports that chaperone molecules from a number of bacteria, including $H$. pylori and C. pneumoniae, induce pro-inflammatory cytokines which may be related to chronic diseases (Da Costa et al., 2004; Lin et al., 2005). CXCL8 is found at significantly high levels in leukocyte tissue infiltrates from gingivitis and chronic periodontitis subjects (Lappin et al., 2003) and evidence supports the notion that these leukocytes are recruited from nearby lymphoid organ/tissue (Kinane et al., 1999; Koulouri et al., 1999), not derived from precursor cells in situ. Chemoattraction of plasma cells and neutrophils (the predominant infiltrating cell type in the gingival space and tissue) is an important step in the immune response to periodontal infection, a step facilitated by CXCL8.

In this study rHtpG induced CXCL8 production by signalling through a non-TLR receptor, CD91, and TLR4. The HUVEC cells do not usually respond to $P$. gingivalis LPS because these cells do not have the TLR2 receptor that $P$. gingivalis LPS has been shown to signal through (Coats etal., 2003). CD91 (also known as the $\alpha$-macroglobulin receptor or LRP-1) has been shown to be a receptor for Hsp90 the human homologue of HtpG

Table 3. Human serum antibodies inhibit induction of CXCL8 secretion by $\mathrm{rHtpG}$ in THP-1 cells.

\begin{tabular}{|c|c|c|c|c|c|}
\hline Subject & $\begin{array}{l}\text { Anti-HtpG } \\
\text { (net RFU) }\end{array}$ & $\begin{array}{l}\text { Treatment serum } \\
\text { (total lgG } \mu \mathrm{g} \mathrm{ml}^{-1} \text { ) }\end{array}$ & $\begin{array}{l}\text { CXCL8 }\left(\mathrm{pg} \mathrm{ml}^{-1}\right) \\
\text { production }\end{array}$ & $\begin{array}{l}\text { Treatment serum } \\
\text { (total } \mathrm{lgG} \mu \mathrm{g} \mathrm{ml}^{-1} \text { ) }\end{array}$ & $\begin{array}{l}\text { CXCL8 }\left(\mathrm{pg} \mathrm{ml}^{-1}\right) \\
\text { production }\end{array}$ \\
\hline 1 & 28651 & 0 & 2017 & 100 & $410^{*}$ \\
\hline 1 & 28651 & 0 & 2133 & 10 & $388^{*}$ \\
\hline 1 & 28561 & 0 & 1997 & 1 & $962^{*}$ \\
\hline 1 & 28561 & 0 & 2091 & 0.1 & 1987 \\
\hline 1 & 28561 & 0 & 2045 & 0.01 & 2173 \\
\hline 2 & 19873 & 0 & 2175 & 10 & $727^{\star}$ \\
\hline 3 & 25500 & 0 & 1983 & 10 & $206^{*}$ \\
\hline 4 & 17855 & 0 & 2001 & 10 & $1121^{*}$ \\
\hline 5 & 18462 & 0 & 1920 & 10 & $989^{*}$ \\
\hline 6 & 0 & 0 & 2175 & 10 & 2105 \\
\hline 7 & 0 & 0 & 1999 & 10 & 1983 \\
\hline 8 & 15743 & 0 & 2084 & 10 & 1720 \\
\hline 9 & 11029 & 0 & 1963 & 10 & $807^{\star}$ \\
\hline 10 & 14449 & 0 & 1844 & 10 & $639^{*}$ \\
\hline
\end{tabular}

${ }^{*}$ Significant mean difference between IgG treated and untreated cells $P=0.05$ ( $t$-test). 
(Basu et al., 2001). When CD91 was blocked there was a significant reduction of CXCL8 production and nearly total reduction of CXCL8 production when both CD91 and TLR4 were blocked by antibody or silenced using siRNA. Finally, we were able to demonstrate that serum IgG from subjects with titres to $\mathrm{rHtpG}$ were able to interfere with CXCL8 production in THP-1 cells. This, combined with our findings that elevated titres to HtpG appear protective in periodontitis (Lopatin et al., 1999), suggests a mechanism whereby antibodies to HtpG (which might cross-react to human Hsp90) could effect CXCL8 production in both antigen presenting and non-antigen presenting cells. This also suggests that a generalized, but as yet uncharacterized control of immune response to chaperones may exist.

CD91 is one of several receptors that endocytose polyanionic ligands including low-density lipoproteins and have important roles in the formation of foam cells and atherosclerotic lesions (Lupu et al., 1994; van Berkel et al., 2005). Recently it has become increasingly apparent that they also have important roles in innate immunity (Peiser et al., 2002a,b). Bacterial chaperones have been shown to enhance both MHC I- and MHC II-mediated responses to chaperoned proteins. Of particular interest here, the response to mycobacterium hsp70 has shown CD91 to be involved in uptake of exogenous HSP:peptide complexes for alternate MHC-I processing and presentation. In addition, CD91 has been shown to bind mammalian gp96, HSP90, HSP70 and calreticulin (Basu et al., 2001). Chylamidial hsp60 activates macrophages and endothelial cells through TLR4 (Bulut et al., 2002) and microbial HSP70 binds CD40 and stimulates CCchemokines production (Wang et al., 2001). P. gingivalis GroEL has recently been shown to signal through TLR2 and TLR4 in THP-1 cells (Argueta et al., 2006). However, this is the first report that microbial HtpG molecules can have similar activity.

The fact that both CD91 and TLR4 are receptors for HtpG may explain our earlier observation that antibodies to $\mathrm{HtpG}$ appear protective. In periodontitis the tissue damage that is the hallmark of the disease is the result of ongoing inflammation mediated by infiltration of the subgingival space by leukocytes, a process mediated by CXCL8 chemoattraction that could result in such a persistent inflammation.

HtpG may well be available as a non-cell-associated protein. Approximately $17 \%$ of subjects participating in a geriatric oral clinical research programme at the University of Michigan (Loesche et al., 1995) were found to have circulating $P$. gingivalis HtpG (C.E. Shelburne, M.D. Coopamah, D.G. Sweier and D.E. Lopatin, unpubl. obs.). In some individuals $\mathrm{HtpG}$ might function as a 'danger signal' as has been described by a number of laboratories for other chaperone molecules (Moseley,
2000). The same availability could also support a role for $\mathrm{HtpG}$ in formation of atherosclerotic plaques (Hajishengallis et al., 2002). The bacteria may enter the blood stream during tooth brushing or dental procedures (Coulter et al., 1990) and this laboratory (Kozarov et al., 2006) and others (Haraszthy et al., 2000; Cairo et al., 2004) have reported the presence of $P$. gingivalis in such plaques from individuals both with and without periodontitis. HtpG, like most chaperones tested, induces a strong humoral response. That response may have consequences in the pathogenesis of chronic diseases like periodontitis (Lopatin et al., 1999) or atherosclerosis. It has also been suggested that chaperones can play roles in both sterile and septic inflammatory responses, and probably have a role in control of the commensal microbial flora (Stewart and Young, 2004). All of these functions are important in the establishment and perpetuation of chronic inflammatory diseases like periodontitis.

Overproduction of CXCL8 has been shown to be an important factor in the pathology of gastric ulcers and possibly gastric carcinoma (Yuan et al., 2004) and inflammatory bowel disease (Daig et al., 1996). Induction of CXCL8 by the H. pylori chaperone Hsp60 (Lin et al., 2005) is thought to be an important part of the disease process of that organism. Passive immunization of mice with anti-CXCL8 has been shown to significantly reduce the growth of transplanted human cancer cells from a variety of tumours (Huang et al., 2002; Mian et al., 2003). Inhibition of CXCL8 production by human serum anti-HtpG as demonstrated here, when considered in light of the CD91 and TLR4 receptor interactions, suggests a novel mechanism by which anti-HtpG is 'protective' (Lopatin et al., 1999) and which can be tested in periodontitis subjects. Validation of such a mechanism could have practical application in controlling that disease. If in addition the mechanism can be generalized it might have significance in several chronic bacterial infections.

\section{Experimental procedures}

\section{Bacterial strains and culture conditions}

Porphyromonas gingivalis W83 were maintained by weekly transfer in an anaerobe chamber (Coy Manufacturing, Grass Lake, MI) at $37^{\circ} \mathrm{C}$ on PRAS Brucella agar plates (Anaerobe Systems, Morgan Hill, CA) in 5\% hydrogen, $10 \%$ carbon dioxide and $85 \%$ nitrogen atmosphere. Broth cultures (BHTS) were grown in modified Brucella Broth (BBL) supplemented with $5 \mathrm{mg} \mathrm{l}^{-1}$ haemin and $5 \mu \mathrm{g} \mathrm{I}^{-1}$ Vitamin K. P. gingivalis W83 $\Delta H$ tp G cells were maintained as previously described (Sweier et al., 2003). Escherichia coli cells for protein expression were grown aerobically in LB broth, supplemented with $100 \mathrm{\mu g} \mathrm{ml}^{-1}$ ampicillin and $34 \mu \mathrm{g} \mathrm{ml}^{-1}$ chloramphenicol. 


\section{Monocyte/HMVEC/HUVEC culture conditions}

THP-1 cells (ATCC TIB-202) were maintained by twice weekly transfer in complete RPMI 1640 medium modified to contain $2 \mathrm{mM}$ L-glutamine, $10 \mathrm{mM}$ Hepes, $1 \mathrm{mM}$ sodium pyruvate, $4.5 \mathrm{~g} \mathrm{l}^{-1}$ glucose, $1.5 \mathrm{gl}^{-1}$ sodium bicarbonate, and supplemented with $10 \%$ fetal bovine serum (FBS) (Invitrogen) and $0.05 \mathrm{mM}$ 2-mercaptoethanol. Cell viabilities were routinely above $95 \%$ as determined by Trypan blue exclusion. Primary human microvascular vein cells (passage 5-7) were a gift from Drs Jacques E. Nör and Peter Polverini and maintained in complete BM-2 medium (Cambrex, Walkersville, MD) as were human umbilical vein cells (Cambrex).

\section{Cloning and purification of $\mathrm{P}$. gingivalis $r H t p G$}

The full-length sequence of $P$. gingivalis $h t p G$ was obtained from The Institute for Genomic Research Comprehensive Microbial Resource database (http://cmr.tigr.org/tigr-scripts/CMR/ $\mathrm{CmrHomePage.cgi).} \mathrm{PCR} \mathrm{primers} \mathrm{were} \mathrm{designed} \mathrm{to} \mathrm{produce} \mathrm{full-}$ length products that were subsequently purified from agarose gels and inserted into $\mathrm{pCR}^{\circledR} \mathrm{T} 7 \mathrm{TOPO}{ }^{\circledR}$ cloning vector following the manufacturer's instructions (Invitrogen, Carlsbad, CA). Clones of One Shot ${ }^{\circledR}$ Chemically Competent E. coli transformed with the vector were ampicillin selected and then screened by PCR using the initial primers. Inserts that produced amplicons of the correct size were sequenced to verify the full-length insert (Biomedical Core, University of Michigan, Ann Arbor, MI). Plasmids with in-frame inserts were used to transform TOP10F' BL21(DE3)pLysS E. coli cells that were subsequently induced with $100 \mu \mathrm{M}$ ITPG for $4 \mathrm{~h}$. The induced fusion protein contains a segment with six consecutive histidine (6xhis) residues preceding the $\mathrm{N}$-terminal of the cloned proteins. The protein was purified by Ni-agarose chromatography (Ni-NTA Agarose, Qiagen, Valencia, $\mathrm{CA}$ ). The $6 \mathrm{xhis}$ component of the fusion protein was removed by enzymatic cleavage of the enterokinase site between the protein and the $6 x$ his and then dialysed into PBS. E. coli LPS was removed by chromatography over a Detoxi-Gel ${ }^{\mathrm{TM}}$ Endotoxin Removing Column (Pierce Chemical, Rockford, IL) and subsequent filtration through a sterile Acrodisc Unit [Mustang E (LPS binding) membrane, $0.2 \mu \mathrm{M}$, Pall, Ann Arbor, MI]. There was no detectable LPS in the final preparation as determined by QCL1000 LAL Assay (sensitivity $0.01 \mathrm{EU} \mathrm{ml}^{-1}$, Cambrex Bio Science, Rockland, ME).

\section{Purification of $\mathrm{P}$. gingivalis $L P S$}

LPS was purified from $P$. gingivalis W83 using the method of Darveau and Hancock (1983). Briefly, pellets of $P$. gingivalis W83 were extracted three times with $0.275 \mathrm{M} \mathrm{MgCl}_{2}$ and the partially purified LPS precipitated with cold ethanol. Finally, the LPS was pelleted by ultracentrifugation, re-suspended in sterile water and lyophilized. Purity was confirmed by double staining (protein and silver stain) of SDS gels by the method of Tsai (1986).

\section{Monocyte exposure to $\mathrm{P}$. gingivalis $r H t p G$ and LPS}

THP-1 cells were harvested and re-suspended in complete RPMI 1640 medium supplemented with 10\% FBS and $0.05 \mathrm{mM}$ 2-mercaptoethanol (ATCC, Gaithersburg, MD) to a final concen- tration of $10^{6}$ cells $\mathrm{ml}^{-1}$. The cell suspension was dispensed into wells $(1 \mathrm{ml})$ of a 24 -well plate and recombinant $\mathrm{rHtpG}$ added to a final concentration of 1,10 or $50 \mu \mathrm{g} \mathrm{ml}^{-1}$. Cells were treated with $P$. gingivalis W83 LPS at a final concentration of $50 \mu \mathrm{g} \mathrm{ml}^{-1}$. Each treatment was carried out in triplicate. The plate was then placed at $37^{\circ} \mathrm{C}$ in an incubator containing a $5 \% \mathrm{CO}_{2}$ in air atmosphere. Triplicate samples were collected and pooled after $30 \mathrm{~min}$ to $8 \mathrm{~h}$ of incubation.

\section{HMVEC/HUVEC exposure to $\mathrm{P}$. gingivalis $r H t p G$ and LPS}

HMVEC or HUVEC cells were seeded into 24-well plates and allowed to grow to confluence. $\mathrm{rHtpG}$ or LPS was added at concentrations of $1.125-100 \mathrm{~g} \mathrm{ml}^{-1}$ (rHtpG) or $1-100 \mathrm{ng} \mathrm{ml}^{-1}$ (LPS) and incubated for $8 \mathrm{~h}$. The supernatants were harvested and assayed for CXCL8 production by ELISA (R\&D Systems, Minneapolis, MN).

For receptor blocking studies HUVEC $\left(10^{6} \mathrm{ml}^{-1}\right.$ well-1) were aliquoted into a 24-well plate. Purified anti-human CD91 or TLR4 (BD Biosciences, San Jose, CA) was then added to a final concentration of $1.0 \mu \mathrm{g} \mathrm{ml}^{-1}$. Both the antibodies were also added in combination at the same concentration for one set of experiments. The cells were incubated for $1 \mathrm{~h}$ at $37^{\circ} \mathrm{C}$, after which rHtpG was added to a final concentration of $50 \mu \mathrm{g} \mathrm{ml}^{-1}$. Incubation was carried out for $8 \mathrm{~h}$ at $37^{\circ} \mathrm{C}$. Supernatants were harvested and analysed for CXCL8 using a commercial ELISA kit (R\&D Systems).

\section{Monocyte exposure to P. gingivalis cells}

Porphyromonas gingivalis and the $P$. gingivalis $\Delta h t p G$ mutant were grown to mid-log phase, centrifuged at $5000 \mathrm{~g}$ for $10 \mathrm{~min}$, and re-suspended in antibiotic-free RPMI 1640 media containing $1 \%$ serum. Bacterial cell density was estimated by determining the $A_{600}$ in a $1 \mathrm{~cm}$ cuvette. Mammalian cells were washed and re-suspended in RPMI 1640 antibiotic-free media containing 1\% serum. The bacteria were added to the washed cells at a ratio of 100 bacteria for each mammalian cell (100:1), unless otherwise stated, and incubated for $8 \mathrm{~h}$. Triplicate samples were collected and pooled after $30 \mathrm{~min}$ to $8 \mathrm{~h}$ of incubation.

\section{ELISA for CXCL8 and TNF}

A commercial 96-well microplate-based kit (R\&D Systems) was used for most CXCL8 and TNF $\alpha$ determinations following the manufacturer's instructions. Initial survey experiments were performed using a protein array (EMD Biosciences, San Diego, CA) according to the manufacturer's instructions.

\section{Real-time PCR for cytokine mRNA}

Total RNA was isolated using either an RNAeasy kit (Qiagen) or Trizol $^{\mathrm{TM}}$ reagent (Invitrogen). Samples were treated with DNAse before reverse transcription and the RNA concentration was determined by UV spectroscopy. SuperScript ${ }^{\mathrm{TM}}$ III (Invitrogen) was used to produce cDNA from $1.0 \mu \mathrm{g}$ of total RNA using random 18-mer primers according to the manufacturer's instructions. GAPDH, 18S rRNA and $\beta$-actin were also used as internal con- 
trols for calculation of the fold change of mRNA. Cytokine mRNA determinations were made using Human Inflammatory Cytokines and Receptors $\mathrm{RT}^{2}$ Profiler ${ }^{\mathrm{TM}}$ PCR Array according to the manufacturer's instructions (SuperArray Biosciences, Frederick, MD). Fold changes were calculated as $2^{-\Delta \Delta C t}$.

\section{Inhibition of CXCL8 production by anti-HtpG antibodies}

$\lg \mathrm{G}$ was isolated by Protein A chromatography from $0.5 \mathrm{ml}$ of whole serum and dialysed into PBS. The IgG concentration was estimated by determination of the $A_{280} / 1.4$. The IgG was treated with immobilized papain to produce $F(a b)$ fragments. The $F(a b)$ fragments $\left(0.01-100 \mu \mathrm{g} \mathrm{ml}^{-1}\right)$ were combined with $50 \mu \mathrm{g} \mathrm{ml}^{-1}$ $\mathrm{rHtpG}$ and incubated overnight at $4{ }^{\circ} \mathrm{C}$. The treated $\mathrm{rHtpG}$ was then diluted in RPMI 1640 with 1\% FBS as noted below and added to THP- 1 cells for $8 \mathrm{~h}$. The supernatants were collected, filtered sterile and assayed for CXCL8 as described.

\section{Serum ELISA for anti-rHtpG}

rHtpG with intact $6 \times$ fusion tags were combined with serum from subjects with diverse medical backgrounds (Loesche et al., 1995). After incubation for $4 \mathrm{~h}$ with shaking at room temperature the samples were transferred to a 96-well plate coated with Ni-NTA (HisSorb ${ }^{\mathrm{TM}}$ Strips, Qiagen), covered with transparent tape and incubated for another $4 \mathrm{~h}$ as before. The plates were washed four times with PBS $+0.05 \%$ Tween 20 and $100 \mu$ l of goat anti-human IgG ( $\gamma$ chain specific) labelled with alkaline phosphatase (100 $\mathrm{ng} \mathrm{ml}^{-1}$ in PBS $+0.5 \%$ BSA) added. After $4 \mathrm{~h}$ of incubation at room temperature the plates were washed again and $100 \mu \mathrm{l}$ of alkaline phosphatase substrate (4-MUP, $100 \mu \mathrm{g} \mathrm{ml}^{-1}$ in $\mathrm{pH} 9.5$ carbonate buffer) was added. The relative fluorescence (RFU) for each well was determined using a Genios ${ }^{\mathrm{TM}}$ (Tecan, Durham, NC) microtitre plate reader. Positive serum samples were confirmed by Western blots using rHtpG diluted in non-reactive human serum. Serum samples were considered positive when the mean for all replicates was greater than $5 \mathrm{SD}$ above the group mean and were positive on the Western blots using purified $\mathrm{rHtpG}$.

\section{siRNA silencing of THP-1 receptor genes}

siRNA for CD91, TLR4 and GAPDH were obtained from Ambion (Austin, TX). THP-1 cells $\left(10^{6} \mathrm{ml}^{-1}\right)$ were combined with $1.5-2.5 \mu \mathrm{g}$ of each siRNA and electroporated (550 V for 100 microseconds) using a Bio-Rad Gene Pulser XCell. The cells were allowed to recover for $48 \mathrm{~h}$ in complete medium and then P. gingivalis $\mathrm{HtpG}\left(50 \mu \mathrm{g} \mathrm{ml}^{-1}\right)$ was added for $8 \mathrm{~h}$. The supernatants from treated and control cultures were harvested and the total RNA was extracted from the cells as described above. Supernatants were assayed for the levels of CXCL8 by ELISA. Total RNA was used to produce CDNA using random primers and the levels of CD91, TLR4 and CXCL8 message were determined by quantitative RT-PCR using specific primer sets (TaqMan Gene Expression Assays, Applied Biosystems, Foster City, CA).

\section{Statistical analysis}

Results are expressed as means \pm SEM. Differences of means calculated using the Student's $t$-test were considered significant for values of $P<0.05$.

\section{Acknowledgements}

PCR primer sequences for cytokines were provided by $\mathrm{Mr}$ Raymond Gleason, 3M Pharmaceuticals, St. Paul, Minnesota. The HMVEC cells were a kind gift from Dr Jacques Nör, University of Michigan School of Dentistry. Supported by NIH/NIDCR DE11117.

\section{References}

Argueta, J.G., Shiota, S., Yamaguchi, N., Masuhiro, Y., and Hanazawa, S. (2006) Induction of Porphyromonas gingivalis GroEL signaling via binding to Toll-like receptors 2 and 4. Oral Microbiol Immunol 21: 245-251.

Baggiolini, M. (1998) Chemokines and leukocyte traffic. Nature 392: 565-568.

Bainbridge, B.W., Coats, S.R., and Darveau, R.P. (2002) Porphyromonas gingivalis lipopolysaccharide displays functionally diverse interactions with the innate host defense system. Ann Periodontol 7: 29-37.

Balasubramanian, A., Munshi, N., Koziel, M.J., Hu, Z., Liang, T.J., Groopman, J.E., and Ganju, R.K. (2005) Structural proteins of Hepatitis $C$ virus induce interleukin 8 production and apoptosis in human endothelial cells. J Gen Virol 86: 3291-3301.

Barker, K.S., Liu, T., and Rogers, P.D. (2005) Coculture of THP-1 human mononuclear cells with Candida albicans results in pronounced changes in host gene expression. $J$ Infect Dis 192: 901-912.

Basu, S., Binder, R.J., Ramalingam, T., and Srivastava, P.K. (2001) CD91 is a common receptor for heat shock proteins gp96, hsp90, hsp70, and calreticulin. Immunity 14: 303313.

van Berkel, T.J., Out, R., Hoekstra, M., Kuiper, J., Biessen, E., and van Eck, M. (2005) Scavenger receptors: friend or foe in atherosclerosis? Curr Opin Lipidol 16: 525535.

Bulut, Y., Faure, E., Thomas, L., Karahashi, H., Michelsen, K.S., Equils, O., et al. (2002) Chlamydial heat shock protein 60 activates macrophages and endothelial cells through Toll-like receptor 4 and MD2 in a MyD88dependent pathway. J Immunol 168: 1435-1440.

Cairo, F., Gaeta, C., Dorigo, W., Oggioni, M.R., Pratesi, C., Pini Prato, G.P., and Pozzi, G. (2004) Periodontal pathogens in atheromatous plaques. A controlled clinical and laboratory trial. J Periodontal Res 39: 442-446.

Coats, S.R., Reife, R.A., Bainbridge, B.W., Pham, T.T., and Darveau, R.P. (2003) Porphyromonas gingivalis lipopolysaccharide antagonizes Escherichia coli lipopolysaccharide at toll-like receptor 4 in human endothelial cells. Infect Immun 71: 6799-6807.

Coulter, W.A., Coffey, A., Saunders, I.D., and Emmerson, A.M. (1990) Bacteremia in children following dental extraction. J Dent Res 69: 1691-1695.

Cutler, C.W., Kalmar, J.R., and Arnold, R.R. (1991) Phagocytosis of virulent Porphyromonas gingivalis by human polymorphonuclear leukocytes requires specific immunoglobulin G. Infect Immun 59: 2097-2104.

Cutler, C.W., Jotwani, R., Palucka, K.A., Davoust, J., Bell, D., and Banchereau, J. (1999) Evidence and a novel hypothesis for the role of dendritic cells and Porphyromonas 
gingivalis in adult periodontitis. J Periodontal Res 34: 406412.

Da Costa, C.U., Wantia, N., Kirschning, C.J., Busch, D.H., Rodriguez, N., Wagner, H., and Miethke, T. (2004) Heat shock protein 60 from Chlamydia pneumoniae elicits an unusual set of inflammatory responses via Toll-like receptor 2 and 4 in vivo. Eur J Immunol 34: 2874-2884.

Daig, R., Andus, T., Aschenbrenner, E., Falk, W., Scholmerich, J., and Gross, V. (1996) Increased interleukin 8 expression in the colon mucosa of patients with inflammatory bowel disease. Gut 38: 216-222.

Darveau, R.P., and Hancock, R.E. (1983) Procedure for isolation of bacterial lipopolysaccharides from both smooth and rough Pseudomonas aeruginosa and Salmonella typhimurium strains. J Bacteriol 155: 831-838.

Darveau, R.P., Arbabi, S., Garcia, I., Bainbridge, B., and Maier, R.V. (2002) Porphyromonas gingivalis lipopolysaccharide is both agonist and antagonist for p38 mitogenactivated protein kinase activation. Infect Immun 70: 18671873.

Gangur, V., Birmingham, N.P., and Thanesvorakul, S. (2002) Chemokines in health and disease. Vet Immunol Immunopathol 86: 127-136.

Gear, A.R., and Camerini, D. (2003) Platelet chemokines and chemokine receptors: linking hemostasis, inflammation, and host defense. Microcirculation 10: 335-350.

Hajishengallis, G., Sharma, A., Russell, M.W., and Genco, R.J. (2002) Interactions of oral pathogens with toll-like receptors: possible role in atherosclerosis. Ann Periodontol 7: 72-78.

Haraszthy, V.I., Zambon, J.J., Trevisan, M., Zeid, M., and Genco, R.J. (2000) Identification of periodontal pathogens in atheromatous plaques. J Periodontol 71: 1554-1560.

Hinode, D., Yoshioka, M., Tanabe, S., Miki, O., Masuda, K., and Nakamura, R. (1998) The GroEL-like protein from Campylobacter rectus: immunological characterization and interleukin-6 and -8 induction in human gingival fibroblast. FEMS Microbiol Lett 167: 1-6.

Huang, S., Mills, L., Mian, B., Tellez, C., McCarty, M., Yang, X.D., et al. (2002) Fully humanized neutralizing antibodies to interleukin-8 (ABX-IL8) inhibit angiogenesis, tumor growth, and metastasis of human melanoma. Am $J$ Pathol 161: 125-134.

Kaufmann, S.H. (1990) Heat shock proteins and the immune response. Immunol Today 11: 129-136.

Kinane, D.F., Lappin, D.F., Koulouri, O., and Buckley, A. (1999) Humoral immune responses in periodontal disease may have mucosal and systemic immune features. Clin Exp Immunol 115: 534-541.

Koulouri, O., Lappin, D.F., Radvar, M., and Kinane, D.F. (1999) Cell division, synthetic capacity and apoptosis in periodontal lesions analysed by in situ hybridisation and immunohistochemistry. J Clin Periodontol 26: 552-559.

Kozarov, E., Sweier, D., Shelburne, C., Progulske-Fox, A., and Lopatin, D. (2006) Detection of bacterial DNA in atheromatous plaques by quantitative PCR. Microbes Infect 8: 687-693.

Lappin, D.F., McGregor, A.M., and Kinane, D.F. (2003) The systemic immune response is more prominent than the mucosal immune response in the pathogenesis of periodontal disease. J Clin Periodontol 30: 778-786.
Lin, S.N., Ayada, K., Zhao, Y., Yokota, K., Takenaka, R., Okada, H., et al. (2005) Helicobacter pylori heat-shock protein 60 induces production of the pro-inflammatory cytokine IL8 in monocytic cells. J Med Microbiol 54: 225233.

Loesche, W.J., Abrams, J., Terpenning, M.S., Bretz, W.A., Dominguez, B.L., Grossman, N.S., et al. (1995) Dental findings in geriatric populations with diverse medical backgrounds. Oral Surg Oral Med Oral Pathol Oral Radiol Endod 80: 43-54.

Lopatin, D.E., Shelburne, C.E., Van Poperin, N., Kowalski, C.J., and Bagramian, R.A. (1999) Humoral immunity to stress proteins and periodontal disease. J Periodontol 70: 1185-1193.

Lupu, F., Heim, D., Bachmann, F., and Kruithof, E.K. (1994) Expression of LDL receptor-related protein/alpha 2-macroglobulin receptor in human normal and atherosclerotic arteries. Arterioscler Thromb 14: 1438-1444.

McLaughlin, J.O., Coulter, W.A., Coffey, A., and Burden, D.J. (1996) The incidence of bacteremia after orthodontic banding. Am J Orthod Dentofacial Orthop 109: 639-644.

Mian, B.M., Dinney, C.P., Bermejo, C.E., Sweeney, P., Tellez, C., Yang, X.D., et al. (2003) Fully human antiinterleukin 8 antibody inhibits tumor growth in orthotopic bladder cancer xenografts via down-regulation of matrix metalloproteases and nuclear factor-kappaB. Clin Cancer Res 9: 3167-3175.

Moseley, P. (2000) Stress proteins and the immune response. Immunopharmacology 48: 299-302.

Peiser, L., Mukhopadhyay, S., and Gordon, S. (2002a) Scavenger receptors in innate immunity. Curr Opin Immunol 14: 123-128.

Peiser, L., De Winther, M.P., Makepeace, K., Hollinshead, M., Coull, P., Plested, J., et al. (2002b) The class A macrophage scavenger receptor is a major pattern recognition receptor for Neisseria meningitidis which is independent of lipopolysaccharide and not required for secretory responses. Infect Immun 70: 5346-5354.

Robertson, M.J. (2002) Role of chemokines in the biology of natural killer cells. J Leukoc Biol 71: 173-183.

Skjolaas, K.A., Burkey, T.E., Dritz, S.S., and Minton, J.E. (2006) Effects of Salmonella enterica serovars Typhimurium (ST) and Choleraesuis (SC) on chemokine and cytokine expression in swine ileum and jejunal epithelial cells. Vet Immunol Immunopathol 111: 199-209.

Socransky, S.S., and Haffajee, A.D. (1992) The bacterial etiology of destructive periodontal disease: current concepts. J Periodontol 63: 322-331.

Socransky, S.S., and Haffajee, A.D. (1997) The nature of periodontal diseases. Ann Periodontol 2: 3-10.

Stewart, G.R., and Young, D.B. (2004) Heat-shock proteins and the host-pathogen interaction during bacterial infection. Curr Opin Immunol 16: 506-510.

Sweier, D.G., Combs, A., Shelburne, C.E., Fenno, J.C., and Lopatin, D.E. (2003) Construction and characterization of a Porphyromonas gingivalis htpG disruption mutant. FEMS Microbiol Lett 225: 101-106.

Tsai, C.M. (1986) The analysis of lipopolysaccharide (endotoxin) in meningococcal polysaccharide vaccines by silver staining following SDS-polyacrylamide gel electrophoresis. J Biol Stand 14: 25-33. 
Wang, Y., Kelly, C.G., Karttunen, J.T., Whittall, T., Lehner, P.J., Duncan, L., et al. (2001) CD40 is a cellular receptor mediating mycobacterial heat shock protein 70 stimulation of CC-chemokines. Immunity 15: 971-983.
Yuan, J.P., Li, T., Chen, H.B., Li, Z.H., Yang, G.Z., Hu, B.Y., et al. (2004) Analysis of gene expression profile in gastric cancer cells stimulated with Helicobacter pylori isogenic strains. J Med Microbiol 53: 965-974. 